\title{
Overheating risk and cooling demand in residential buildings: performance prediction and improvement using a prescriptive approach
}

\author{
Ameer Wadi, Mahmoud Alhayek, Ulrich Pont ${ }^{*}$, and Ardeshir Mahdavi \\ Department of Building Physics and Building Ecology, TU Wien, Vienna, Austria
}

\begin{abstract}
Depending on general climatic trends and specific (urban) microclimatic conditions, the reliable estimation of the overheating risk in buildings has become increasingly important. As such, detailed simulation of the related phenomena can provide useful information. However, deployment of detailed simulation involves a number of challenges, including time and effort expenditures not accounted for in typical building delivery processes. In this context, careful application of prescriptive methods may provide - at least for a specific class of applications - a reasonable alternative. The present contribution explores this possibility via a specific case study involving a large sample of residential buildings in Gaza, Palestine. This sample includes some fifty multi-unit apartment buildings representing the bulk of residential building stock in Gaza. These buildings were assessed via both numeric simulation and regression-based methods, assuming the latter can provide the basis for development and validation of a prescriptive approach. Toward this end, a number of independent variables were considered and the level of their association with the computed values of the designated building performance indicators was observed. Comparison of the regression-based and simulation-based methods revealed a reasonable level of agreement. This suggests that the proposed prescriptive method may provide an attractive alternative to highly detailed simulation.
\end{abstract}

\section{Introduction}

The contribution of buildings to both the total energy consumption and climate harming GHG (Green House Gas) emissions is well-known. Thus, there is a world-wide interest pertaining to adopt energy efficiency measures in the building sector. As such, measures need to be globally implemented to reach sustainability goals in the building sector via subsidy initiatives and performance threshold values stipulated by laws, standards and guidelines. Regulative instruments such as energy codes are considered to be one of the most effective policy mechanism, in their enforcement is secured [1].

In general two different approaches regarding the evaluation of energy efficiency of (yet to be built or yet to be refurbished) buildings can be distinguished:

The performance-based approach requires sophisticated calculation or simulation methods to derive key performance indicators (KPIs), whose bench-mark values are mandated. Such methods provide very comprehensive and detailed insight into the 
performance of buildings and the tools are considered to be state-of-the-art. Moreover, via parametric modifications, the sensitivity of specific building designs regarding design changes or changing boundary conditions can be evaluated easily. However, the performance-based approach requires in-depth knowledge and experience in use of the tools. Furthermore, it typically requires large expenditure of effort, time and cost.

The prescriptive approach follows a different philosophy. Thereby, a combination of different geometric and semantic design variables is used to set up so called prescriptive variables/indicators. Different combinations of geometry and semantic data would lead to different performance indicator values. If this connection is known, it is possible to define threshold values for the prescriptive variables, so that planners can simply consider these thresholds to ensure a certain performance of their building design. It is obvious that such prescriptive indicators may not provide the same specificity and resolution as KPIs derived via the performance-based approach. Nonetheless, they could facilitate building quality benchmarking in case the performance-based approach cannot be deployed. Despite the fact that such codes may lead to missing opportunities to increase energy efficiency in some cases, they can still contribute to performance improvement of large building populations if they are based on comprehensive and systematic parametric simulation results and are reviewed by a panel of experts [2].

In this contribution, we illustrate the potential of the prescriptive approach pertaining to cooling demand and overheating tendency as possibility for increased building sustainability for the Gaza Strip (Palestine). Gaza Strip has very limited energy resources and is entirely dependent on importing such resources from neighbouring countries. It is thus essential to develop energy efficiency measures towards creating a more sustainable built environment. In such context, a prescriptive method can support efforts toward better building designs. Specifically, the goal of the efforts described in this contribution (see also [3] and [4]) is to create a prescriptive building index based on the regression analysis of numeric simulation results. The index can be used by architects and engineers during the early stages of the design process to account for energy efficiency in buildings. It will use simple characteristics of building envelope and can be easily derived from design plans.

Past research efforts pertaining to similar topics, and thus forming a base for the present study include - amongst others - Mahdavi and Gurtekin [5], Mahdavi and Pessenlehner [6][7], Markovic et al. [8], and Pont and Mahdavi [9].

\section{Methodology}

\subsection{Objective}

The main objective of this contribution is to deliver a proof of concept regarding the utilization of prescriptive indicators for design decisions pertaining to the cooling energy demand in the specific context of Gaza.

\subsection{Building sample and thermal envelope quality.}

A building sample of 50 typical residential buildings from the Gaza strip was generate. All of these buildings are multi-storey, multi-family buildings, but with variance in building design variables regarding buildings morphology, glazing area, and number of floors. An overview of the buildings and some of their characteristics and prescriptive indicators is provided at the end of this contribution (Figure 6). Table 1 provides an overview of the basic assumptions regarding the thermal quality of the buildings' envelopes. 
Table 1. U-values and thermal properties of buildings' envelopes.

\begin{tabular}{|c|c|c|}
\hline Building Element & $\begin{array}{c}\text { Construction layers (Thickness [m]; thermal } \\
\text { conductivity }\left[\mathrm{W} \cdot \mathrm{m}^{-1} \cdot \mathrm{K}^{-1}\right] \text { ) }\end{array}$ & $\begin{array}{c}\text { U-value } \\
{\left[\mathrm{W} \cdot \mathrm{m}^{-2} \cdot \mathrm{K}^{-1}\right]}\end{array}$ \\
\hline $\begin{array}{l}\text { External Roof (ribbed slab } \\
\text { system) }\end{array}$ & $\begin{array}{c}\text { Reinforced concrete }(0.08 ; 2.3) \\
\text { Hollow block with reinf. concrete }(0.17 ; 0.92) \\
\text { Plaster }(0.025 ; 1.4)\end{array}$ & 2.668 \\
\hline $\begin{array}{l}\text { External Wall (Hollow Block } \\
\text { Wall) }\end{array}$ & $\begin{array}{c}\text { Outside Plaster }(0.025 ; 1.4) \\
\text { Block Wall }(0.2 ; 0.56) \\
\text { Inside Plaster }(0.025 ; 0.7) \\
\end{array}$ & 1.784 \\
\hline Floor to ground & $\begin{array}{c}\text { Tiles }(0.05 ; 1.3) \\
\text { Sand with cement }(0.1 ; 2) \\
\text { Reinforced concrete }(0.08 ; 2.3) \\
\text { Hollow block with reinf. concrete }(0.17 ; 0.92)\end{array}$ & 2.338 \\
\hline Interior Ceiling & $\begin{array}{c}\text { Tiles }(0.05 ; 1.3) \\
\text { Sand with cement }(0.1 ; 2) \\
\text { Reinforced concrete }(0.08 ; 2.3) \\
\text { Hollow block with reinf. concrete }(0.17 ; 0.92) \\
\end{array}$ & 1.462 \\
\hline Interior Wall & $\begin{array}{c}\text { Outside Plaster }(0.025 ; 1.4) \\
\text { Block Wall }(0.1 ; 0.56) \\
\text { Inside Plaster }(0.025 ; 0.7)\end{array}$ & 2.028 \\
\hline Ceiling to unheated & $\begin{array}{c}\text { Reinforced concrete }(0.08 ; 2.3) \\
\text { Hollow block with reinf. concrete }(0.17 ; 0.92) \\
\text { Plaster }(0.025 ; 1.4)\end{array}$ & 2.668 \\
\hline Wall to unheated & $\begin{array}{c}\text { Outside Plaster }(0.025 ; 1.4) \\
\text { Block Wall }(0.2 ; 0.56) \\
\text { Inside Plaster }(0.025 ; 0.7) \\
\end{array}$ & 1.784 \\
\hline Windows (single glazing) & Clear glass $(0.003 ; 0.9)$ & 5.894 \\
\hline Doors & Wood $(0.0254 ; 0.15)$ & 6.68 \\
\hline
\end{tabular}

\subsection{Simulation input parameters and settings}

EnergyPlus (Version 8.9 [10]) and OpenStudio [11] were used as simulation engine. Buildings were modelled in SketchUp [12]. Obtaining accurate weather data for the Gaza strip is difficult due to the unavailability of default weather files in most simulation tools for this location. Thus, Meteonorm [13] was used to generate a weather data file, based on surrounding weather stations' data and considering the specifics of the location (transition zone between coastal area wetlands and dry desert region). Table 2 illustrates the simulation settings used in the EnergyPlus simulations. Figures 1 and 2 illustrate assumptions regarding urban embedment and shading obstructions for the simulations of the sample buildings.

Table 2. Simulation settings / Boundary conditions

\begin{tabular}{|l|l|c|}
\hline \multicolumn{1}{|c|}{ Input parameters } & \multicolumn{1}{c|}{ Unit } & Value \\
\hline Air-conditioning design temperature & ${ }^{\circ} \mathrm{C}$ & 25 \\
\hline Heating design temperature & ${ }^{\circ} \mathrm{C}$ & 20 \\
\hline HVAC System & Default Ideal loads air systems & \\
\hline Infiltration rate & $\mathrm{h}^{-1}$ & 0.2 \\
\hline Ventilation rate & $\mathrm{h}^{-1}$ & 0.4 \\
\hline People & $\mathrm{m}^{2}$. Person $^{-1}$ & 20 \\
\hline Occupancy activity level & $\mathrm{W}$. Person $^{-1}$ & 100 \\
\hline Lighting load & ${\mathrm{W} . \mathrm{m}^{-2}}^{-1}$ & 1.3 \\
\hline Electric Equipment Load & W.m & 3 \\
\hline Shading & Horizontal overhang for Windows (Balconies) \\
\hline Thermal zoning & One floor zoning \\
\hline
\end{tabular}



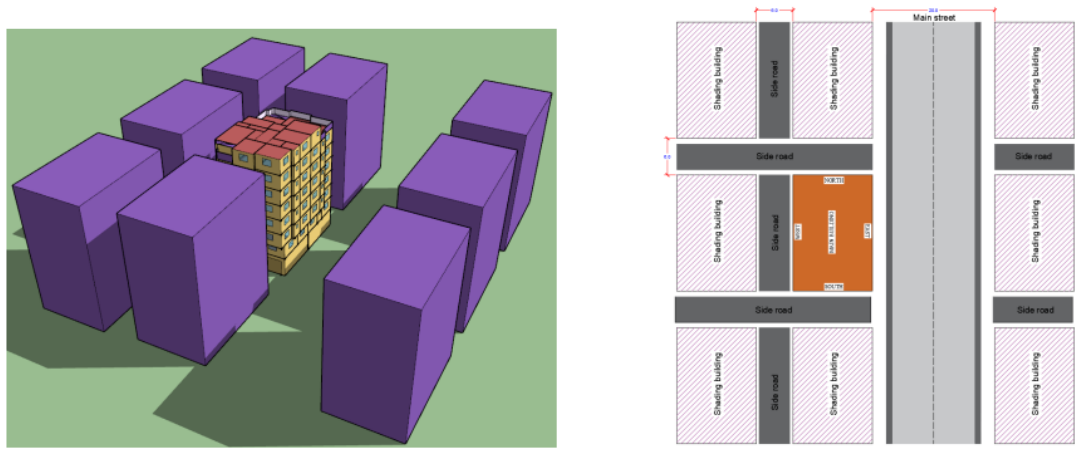

Fig. 1 (left) and Fig. 2 (right). Isometry and Plan view of the outside obstructions / shading settings as assumed for the sample buildings.

\subsection{Prescriptive building variables.}

Table 3 illustrates the examined prescriptive building variables (prescriptive indicators). Note that in Figure 6 some of the variables are illustrated for each of the sample buildings. Some of the indicators consider very simple planning parameters (e.g. volume, conditioned floor area), while others integrate even orientation (e.g. effective Window to Wall ratio). A detailed description of each of the variables and associated derivation methods from architectural plans can be found in [3].

Table 3. Building Design variables

\begin{tabular}{|c|c|}
\hline Abbreviation & Description \\
\hline \multicolumn{2}{|l|}{ Physical properties } \\
\hline $\mathrm{V}$ & Conditioned volume $\left[\mathrm{m}^{3}\right]$ \\
\hline $\mathrm{A}_{\mathrm{cn}}$ & Conditioned floor area $\left[\mathrm{m}^{2}\right]$ \\
\hline A & Thermal building envelope area $\left[\mathrm{m}^{2}\right]$ \\
\hline $\mathrm{A}_{\mathrm{w}}$ & Window area $\left[\mathrm{m}^{2}\right]$ \\
\hline$A_{\text {wall }}$ & Area of wall $\left[\mathrm{m}^{2}\right]$ \\
\hline \multicolumn{2}{|l|}{ Form factors } \\
\hline $\mathrm{C}$ & Compactness (surface area to volume ratio) $\left[\mathrm{m}^{-1}\right]$ \\
\hline $\mathrm{RC}$ & Relative compactness \\
\hline $1_{\mathrm{c}}$ & Characteristic length \\
\hline \multicolumn{2}{|c|}{ Properties of transparent elements of building envelope } \\
\hline WWR & Window to wall ratio [\%] \\
\hline $\mathrm{WWR}_{\mathrm{os}}$ & Effective window to wall ratio [\%] \\
\hline WFR & Window to floor ratio [\%] \\
\hline \multicolumn{2}{|l|}{ Thermal properties } \\
\hline $\mathrm{U}_{\mathrm{e}}$ & Effective average envelope U-value $\left[\mathrm{W} \cdot \mathrm{m}^{-2} \cdot \mathrm{K}^{-1}\right]$ \\
\hline $\mathrm{C}_{\mathrm{t}}$ & Thermal compactness [m] \\
\hline LEK & LEK Value \\
\hline $\mathrm{A}_{\mathrm{e}}$ & Effective envelope area $\left[\mathrm{m}^{2}\right]$ \\
\hline
\end{tabular}




\section{Results}

Figure 3 shows the simulated overheating index (see [6]) for all sample buildings (in average $12138 \mathrm{Kh} \cdot \mathrm{a}^{-1}$ ). It is evident that these buildings have severe overheating issues.

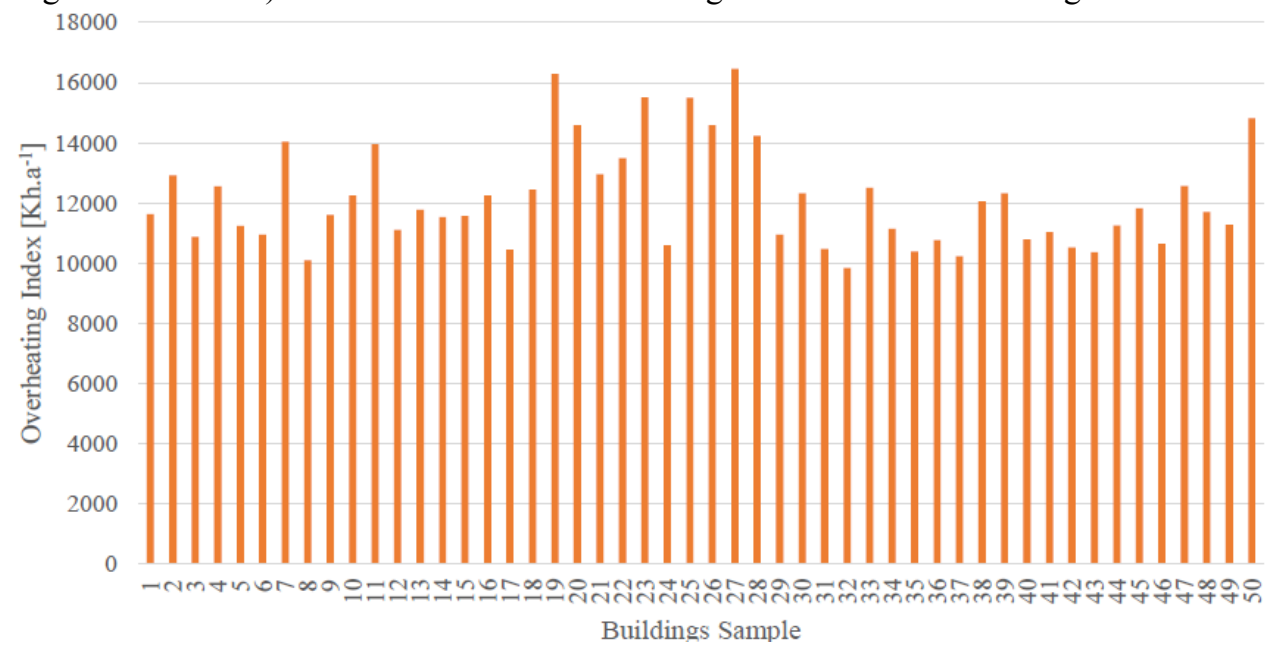

Fig. 3. Overheating indices for all 50 sample building, (indicator based on [6]).

The relationship of the different design variables with the overheating tendency was explored via linear regression. Thereby, the different candidate prescriptive variables displayed $\mathrm{R}^{2}$ values between 0.1426 and 0.5561 . The highest $\mathrm{R}^{2}$ could be found in the regression analysis of the derived overheating hours indicator and the Windows to Floor ratio (WFR) as per Figure 4.

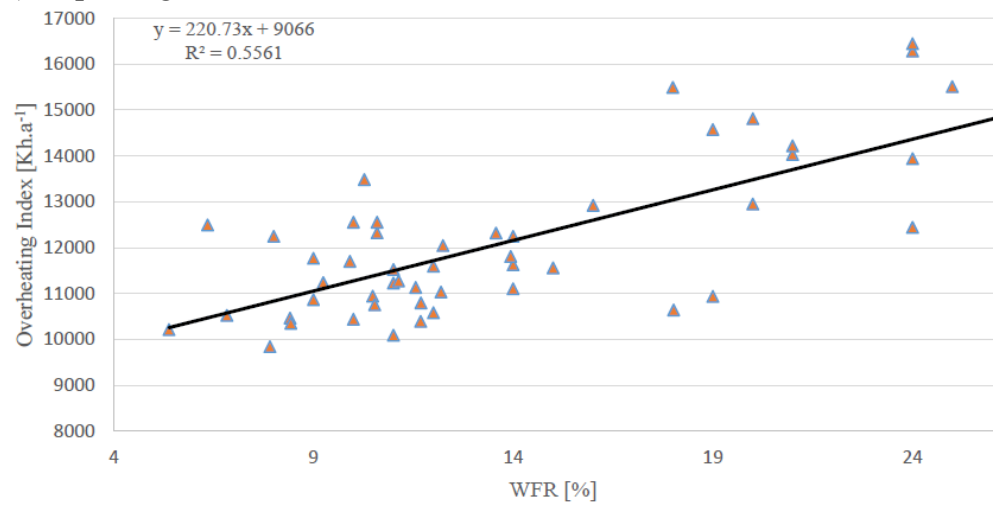

Fig. 4. Overheating indicator values vs. Window to Floor ratio (WFR)

Subsequently, combinations of different prescriptive indicators were explored toward a better fit to the overheating indicators. One rather good fit was found in a combination of the shape factor $(\mathrm{SF})$ and the effective Window to Wall ratio $\left(\mathrm{WWR}_{\mathrm{OS}}\right)$. Equation (1) illustrates the resulting regression equation. Figure 5 illustrates the performance of the derived equation in comparison to the results obtained from the simulation.

$Y^{\prime}=6450.359+6779.444 \mathrm{X}_{1}+178.476 \mathrm{X}_{2}$

$\mathrm{Y}^{\prime}$... predicted value (overheating index)

$\mathrm{X}_{1} \ldots$ Shape Factor

$\mathrm{X}_{2} \ldots$ effective Window to Wall ratio 


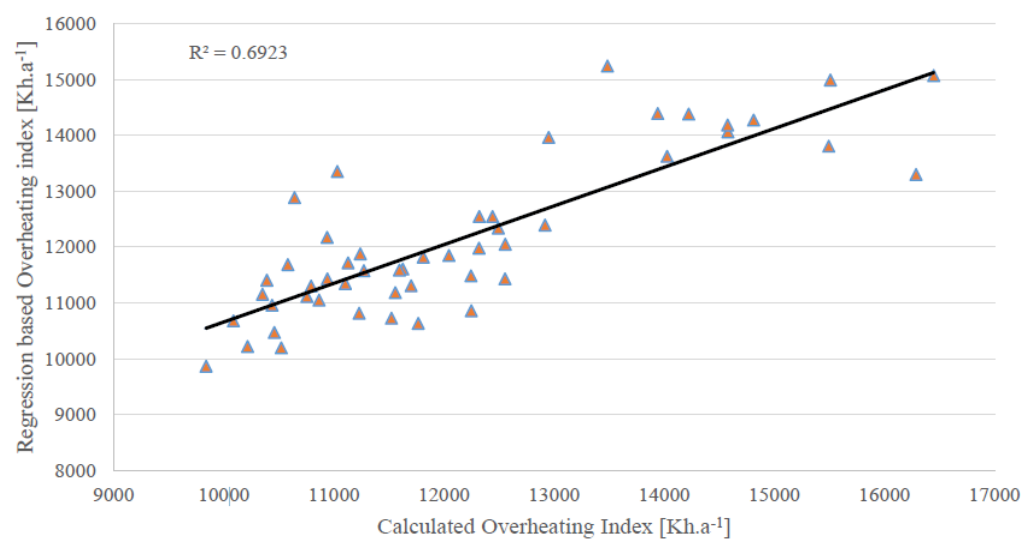

Fig. 5. Simulated versus regression-based overheating index

\section{Conclusions and Future Research}

The present contribution explored the potential of regression-based processing of simulation results to provide a basis for the derivation of simple prescriptive methods for benchmarking buildings' thermal quality. Specifically, the relationship of easy-to-derive building design variables (such as shape factor or window-to-wall ratio) with key performance indicators (such as overheating index) was studies, focusing on the densely built context of Gaza. Prescription of bench-mark values for such design variables is expected to warrant a certain overall quality assurance for the general building population. This approach is not meant to replace detailed simulation tools, which should be of course deployed whenever possible. Needless to say, that the underlying simulation results must be ultimately validated through comparison with the actual energy use data, even if the latter is difficult to come by due technical and procedural challenges. Moreover, the present results consider a rather specific climatic context. It might be beneficial to consider additional variables that would account for the variance of the contextual circumstances, including microclimatic conditions. Further limitations of the study pertain to its focus on residential buildings only.

The research presented in this study were supported in part by the Austrian Partnership Program in Higher Education and Research for Development (APPEAR), a program of the Austrian Development Cooperation (ADC) that was implemented by the Austrian Agency for International Cooperation in Education and Research (OeAD).

\section{References}

1. S. Koeppel, D. Ürge-Vorsatz. Assessment of policy instruments for reducing greenhouse gas emissions from buildings. Report for the UNEP-Sustainable Buildings and Construction Initiative, Central European University, Budapest. ISBN: 978-96387714-0-7. (2007)

2. R. Higa, D. McLean, J. Mack, J. McHugh. In Praise of Prescriptive Codes, Rules of Thumb and Design Guidelines: How Do We Compare with 50\% AEDG? In ACEEE Summer Study on Energy Efficiency in Buildings, 12-17 August 2012, Pacific Grove, CA. (2012). 
3. A. Wadi. Overheating and cooling demand in residential buildings: a simplified index for the early stages of the design process; Supervisor: A. Mahdavi, U. Pont; TU Wien 2019; final examination: 2019-01-22.

4. M. Alhayek. The Potential for Energy Saving through a Simplified Prescriptive Method as an Alternative to the Performance-Based Approach to Buildings' Thermal Quality; Supervisor: A. Mahdavi, U. Pont; TU Wien, 2019; final examination: 201901-22.

5. A. Mahdavi, B. Gurtekin. Shapes, Numbers, and Perception: Aspects and Dimensions of the Design Performance Space". In: Proceedings of the 6th International Conference: Design and Decision Support Systems in Architecture. Ellecom: The Netherlands. (2002) pp. 291-300.

6. W. Pessenlehner, A. Mahdavi. Building Morphology, Transparence, and Energy Performance. in: "Building Simulation", (2003), ISBN: 90-386-1566-3; S. 1025 - 1032.

7. A. Mahdavi, W. Pessenlehner. Über Gebäudemorphologie, Transparenz und Energie Performance; Österreichische Ingenieur- und Architekten-Zeitschrift (ÖIAZ), 149 (2004), 2-3; S. 88 - 94.

8. M. Markovic, U. Pont, A. Mahdavi. The Potential of Descriptive Building Specifications as an Alternative to Detailed Normative Calculations; in Applied Mechanics and Materials, (2019), 887; 164 - 171.

9. U. Pont, A. Mahdavi. Evaluation of Prescriptive Indicators for Building Performance A Ranking Based Approach; Applied Mechanics and Materials, (2019), 887; 172 180.

10. Department of Energy: EnergyPlus Version 8.9 (www.energyplus.net)

11. OpenStudio (www.openstudio.net)

12. SketchUp (www.sketchup.com)

13. Meteotest Meteonorm (www.meteonorm.com) 


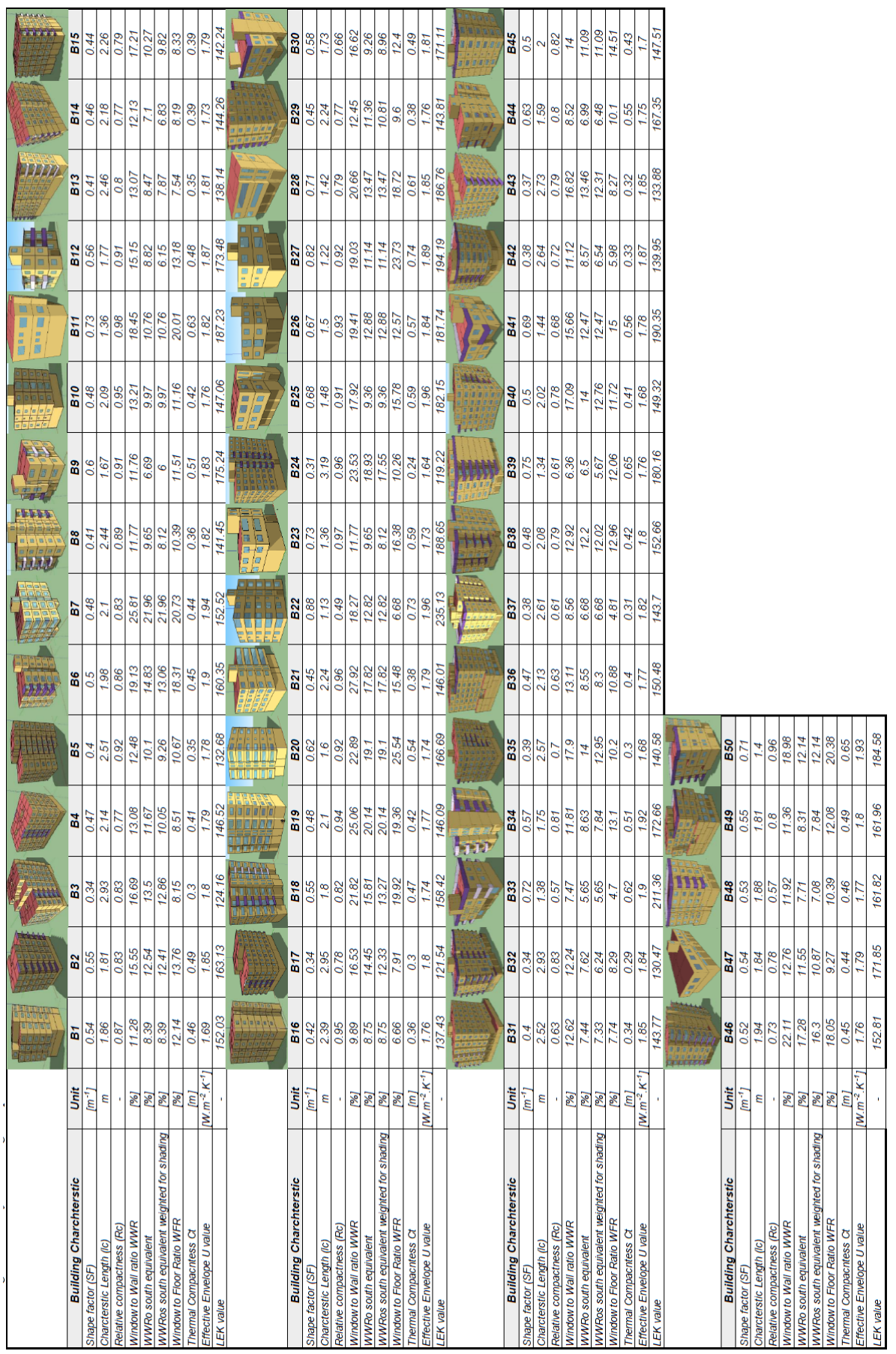

Fig. 6. Building sample and derived values of a number of candidate variables to be implemented in a prescriptive building quality assurance approach 